\title{
Sikap terhadap Pensiun, Perencanaan Pensiun, dan Kualitas Hidup pada Karyawan dalam Masa Persiapan Pensiun
}

\author{
Aulia Iskandarsyah ${ }^{1}$, Hari Setyowibowo ${ }^{2}$ \\ ${ }^{1}$ Departemen Psikologi Klinis, Fakultas Psikologi Universitas Padjadjaran \\ ${ }^{2}$ Departemen Psikologi Pendidikan, Fakultas Psikologi Universitas Padjadjaran \\ Jalan Raya Bandung Sumedang KM.21 Jatianangor - Sumedang 45363 \\ E-mail: a.iskandarsyah@unpad.ac.id
}

\begin{abstract}
ABSTRAK
Tujuan dari penelitian ini adalah untuk mengevaluasi hubungan antara sikap terhadap pensiun, perencanaan pensiun, dan kualitas hidup pada karyawan dalam Masa Persiapan Pensiun (MPP). Penelitian ini menggunakan desain crosssectional. Sebanyak 300 karyawan dalam masa persiapan pensiun di PT. X dijaring dengan menggunakan teknik purposive sampling dalam 3 termin. Partisipan mengisi form demografis standar, skala sikap terhadap pensiun, skala perencanaan pensiun, dan WHOQOL-BREF. Hasil dari analisis regresi menunjukkan bahwa perencanaan pensiun adalah prediktor yang signifikan untuk domain fisik $(\beta=0,22, p=0,01)$, domain psikologis $(\beta=0,4, p=0,01)$, dan domain lingkungan $(\beta=0,24, p=0,01)$ dari kualitas hidup, sementara sikap terhadap pensiun tidak secara signifikan memprediksi kualitas hidup. Hasil penelitian ini menunjukkan bahwa perencanaan pensiun adalah prediktor dari kualitas hidup karyawan yang sedang berada dalam masa persiapan pensiun. Selain itu, pentingnya menyediakan program persiapan pensiun secara adekuat dan mencukupi, memungkinkan para karyawan membuat perencanaan pensiun secara lebih baik.
\end{abstract}

Kata kunci: sikap terhadap pensiun; perencanaan pensiun; kualitas hidup; masa persiapan pensiun

\section{Attitude Toward Retirement, Retirement Planning, and Quality of Life Among Employees in Retirement Preparation Period}

\begin{abstract}
This study aims to evaluate relationship of attitude toward retirement, retirement planning, and quality of life among employees in retirement preparation period. The study used the cross-sectional design. Three hundred employees who were in the retirement preparation period at PT. X were recruited through purposive sampling technique in 3 terms. Participants completed a standard demographic form, attitude toward retirement, retirement planning scale, and the WHOQOL-BREF. The regression analysis results showed that retirement planning was a significant predictor of physical domain $(\beta=0,22, p=0,01)$, psychological domain $(\beta=0,4, p=0,01)$, and environmental domain $(\beta=0,24, p=0,01)$ of quality of life, whereas attitude toward retirement did not. Our results suggest that retirement planning is a predictor of quality of life of employees in retirement preparation period. Therefore, it highlights the importance of providing adequate and sufficient retirement preparation program that enable the employee to make a better retirement planning.
\end{abstract}

Keyword: attitude toward retirement; retirement planning; quality of life; retirement preparation period

\section{PENDAHULUAN}

Istilah pensiun pada umumnya dihubungkan dengan berakhirnya masa bakti seseorang pada suatu institusi atau dalam Kamus Besar Bahasa Indonesia diartikan sebagai tidak bekerja lagi karena masa tugasnya sudah selesai (Kamus Besar Bahasa Indonesia, 2016). Di Indonesia, pada umumnya batasan usia pensiun bagi Pegawai Negeri Sipil,
BUMN, ataupun swasta berkisar pada usia 58 tahun bagi Pejabat Administrasi dan 60 tahun bagi Pejabat Pimpinan Tinggi (Badan Kepegawaian Negara, 2014). Pensiun bisa dikatakan sebagai salah satu peristiwa perubahan sosial yang penting di masa dewasa akhir yang membutuhkan adanya restrukturisasi terhadap rutinitas hidup sehari-hari dan kontak sosial (Weiner, 2003), sehingga memungkinkan munculnya masalahmasalah psikologis mulai dari masalah ringan sampai 
dengan masalah yang memerlukan bantuan profesional. Penelitian di negara Eropa menunjukkan adanya hubungan antara masa pensiun dengan penurunan status kesehatan, penurunan aktivitas, dan kondisi kesehatan kronis (Hessel, 2016).

Berdasarkan data statistik, proporsi penduduk Indonesia yang telah memasuki usia pensiun (60 tahun ke atas) sekarang ini telah mencapai $8,9 \%$ dari total penduduk dan angka ini diperkirakan akan terus meningkat menjadi $21,4 \%$ dari total penduduk Indonesia di tahun 2050 (Pusat Data dan Informasi Kementerian Kesehatan RI, 2016). Melihat dari kondisi aktual tersebut, adanya program pendampingan yang terstruktur sebagaimana dilakukan pada mereka yang ada dalam usia produktif menjadi sangat penting, sehingga mereka bisa memasuki masa pensiun dengan nyaman dan bisa mencapai visi dari pemerintah, yaitu untuk "Menjadikan Lanjut Usia Indonesia Sejahtera".

Terdapat beberapa faktor yang membantu seseorang untuk bisa menyesuaikan diri dengan tuntutan masa pensiun secara baik, yaitu faktor personal, sosial, dan finansial (Szinovacz, 2003). Ketersediaan faktor-faktor tersebut tidak hanya memengaruhi kemampuan untuk menyesuaikan diri dengan masa pensiun, namun juga memengaruhi sikapnya terhadap pensiun (Reitzes, 2006), kualitas hidup (Alvarenga, Kiyan, Bitencourt, \& Wanderley, 2009), dan kesejahteraan mereka setelah masa pensiun (Kubicek, Korunka, Raymon, \& Hoonakker, 2011).

Para ahli memiliki pandangan bahwa untuk bisa menghadapi dan menyesuaikan diri dengan masa pensiun secara baik, diperlukan adanya sikap yang positif terhadap pensiun dan juga perencanaan masa pensiun yang baik (Lim, 2003). Sikap terhadap pensiun dapat didefinisikan sebagai preferensi, keinginan, atau keyakinan seseorang yang berkaitan dengan proses pensiun, sedangkan perencanaan pensiun dapat didefinisikan sebagai tindakan atau prosedur yang dimiliki seseorang yang berkaitan dengan berbagai masalah spesifik di masa pensiun (Turner, 1989). Penelitian sebelumnya terhadap 168 karyawan yang mendekati masa pensiun di Amerika menemukan bahwa sikap terhadap pensiun berhubungan secara signifikan dengan tingkat depresi, kecemasan, dan kesejahteraan psikologis (Foster, 2008). Lebih lanjut, penelitian lainnya mengidentifikasi delapan faktor yang berhubungan dengan sikap terhadap pensiun, yaitu tingkat pendapatan, status pernikahan, ekspektasi terhadap masa pensiun, perencanaan pensiun, antisipasi terhadap pensiun, self-competence (kompetensi diri), self-esteem (keberhargaan diri), dan depresi (Mutran, Reitzes, \& Fernandez, 1997).

Selain sikap terhadap pensiun, perencanaan pensiun pun dianggap sebagai hal yang menentukan keberhasilan seseorang untuk bisa beradaptasi dengan masa pensiunnya kelak. Meskipun demikian, pada kenyataanya hanya sedikit orang yang melakukan perencanaan masa pensiun dikarenakan mereka terlalu sibuk dengan pekerjaan sekarang, tidak bisa, atau pun tidak mau membuat perencanaan masa depan (Adams \& Rau, 2011). Di Indonesia, permasalahan penyesuaian diri dan permasalahan psikologis lainnya pada mereka yang meghadapi masa pensiun masih belum banyak diteliti secara sistematis. Selain itu, meskipun telah ada beberapa institusi pemerintah, seperti BUMN maupun swasta yang sudah memiliki program persiapan masa pensiun, pada pelaksanaanya hanya beberapa institusi saja yang telah memiliki program secara terstruktur, antara lain perusahaan $\mathrm{X}$ tempat penelitian ini dilaksanakan. Deteksi dini mengenai kesiapan memasuki masa pensiun akan sangat bermanfaat untuk penyusunan program yang tepat. Dari penelusuran pustaka secara daring, di Indonesia sampai dengan saat ini belum banyak studi sistematis mengenai persiapan masa pensiun yang dipublikasikan dalam jurnal akademik dan lingkup penelitiannya pun lebih menekankan pada masa setelah seseorang menjalani pensiun.

Berdasarkan fenomena tersebut, penelitian ini bertujuan untuk mengevaluasi hubungan antara sikap terhadap pensiun, perencanaan pensiun, dan kualitas hidup pada karyawan dalam Masa Persiapan Pensiun (MPP) di perusahaan $\mathrm{X}$.

\section{METODE}

\section{Desain dan Partisipan Penelitian}

Desain penelitian ini adalah cross-sectional dengan menggunakan metode survei, dimana pengukuran atas variabel-variabel penelitian dilakukan dalam satu waktu pengukuran (Shaughnessy, 2012). Populasi penelitian adalah seluruh karyawan PT. X yang sedang dalam masa persiapan pensiun, yaitu 1-3 tahun, sedangkan sampel penelitian adalah karyawan PT. X yang sedang dalam masa persiapan pensiun yang direkrut dengan menggunakan teknik purposive sampling dalam 3 (tiga) tahap, yaitu bulan April, Mei, dan Juni 2014. Adapun kriteria inklusi yang digunakan dalam penelitian ini adalah (1) status karyawan tetap, (2) sedang dalam masa persiapan pensiun (1-2 tahun menjelang pensiun), dan (3) bersedia secara sukarela menjadi partisipan.

\section{Instrumen Pengukuran}

Dalam penelitian ini, terdapat beberapa alat ukur yang digunakan. Pertama, daftar isian demografis standar untuk memperoleh data demografis partisipan mengenai usia, status perkawinan, tingkat pendidikan, status pekerjaan, masa kerja, status asuransi, dan status kesehatan.

Kedua, Attitude Toward Retirement and Retirement Planning Scale untuk mengukur skala sikap dan perencanaan masa pensiun (Turner, 1989) yang diadaptasi ke dalam bahasa Indonesia dengan metode forward translation. Alat ukur ini terdiri atas 4 butir soal. Perencanaan terhadap masa pensiun diukur oleh butir nomor 1 dan 2. Butir nomor 1 mengukur tingkat 
perencanaan pensiun dengan alternatif pilihan 1 (tidak sama sekali) sampai dengan 4 (banyak), sedangkan butir nomor 2 mengukur penilaian pribadi atas perencanaan pensiun yang sudah dilakukan jika dibandingkan dengan orang lain dengan alternatif pilihan 1 (kurang), 2 (sama), dan 3 (lebih). Hasil penjumlahan butir 1 dan 2 menunjukkan skor perencanaan pensiun, dimana semakin besar skor berarti semakin besar perencanaan yang dilakukan. Sikap terhadap pensiun diukur oleh butir nomor 3 yang memiliki alternatif jawaban mulai dari 1 (sangat tidak saya harapkan) sampai dengan 4 (saya harapkan), dimana semakin tinggi skor berarti semakin positif sikap terhadap pensiun. Butir nomor 4 mengukur tingkat kepuasan atas informasi mengenai pensiun yang diberikan oleh perusahaan dengan alternatif jawaban mulai dari 1 (sangat tidak memuaskan) sampai dengan 5 (sangat memuaskan), dimana semakin tinggi skor berarti semakin puas seseorang terhadap informasi yang diperoleh.

Ketiga, World Health Organization Quality of Life (WHOQOL)-BREF yang digunakan untuk mengukur penilaian atas kualitas hidup seseorang (World Health Organization, 1997). Alat ukur ini dikembangkan oleh WHO melalui uji coba lapangan multisenter dari 23 negara. Alat ini adalah kuesioner laporan diri yang terdiri dari 26 butir soal, masing-masing butir mewakili satu aspek kehidupan yang dianggap memiliki kontribusi terhadap kualitas hidup seseorang. Sebanyak 24 butir soal mengukur 4 (empat) domain, yaitu kesehatan fisik (misalnya mobilitas, rasa sakit, dan ketidaknyamanan; 7 butir), kesehatan psikologis (misalnya citra tubuh dan penampilan, perasaan negatif, dan harga diri; 6 butir), hubungan sosial (misalnya hubungan pribadi, dukungan sosial; 3 butir) dan lingkungan (misalnya sumber daya keuangan, kesehatan dan sosial, serta lingkungan fisik; 8 butir). Sebanyak 2 butir soal lainnya mengukur persepsi keseluruhan atas kualitas hidup dan kesehatan secara umum. Alat ukur ini menggunakan skala 5-poin (1 sampai 5) dengan skor yang lebih tinggi menunjukkan tingkat kualitas hidup yang lebih tinggi. Alat ukur ini telah tersedia dalam versi Bahasa Indonesia dan telah divalidasi, memiliki reliabilitas yang memadai untuk semua domain dengan koefisien Cronbach's $\alpha$ berkisar antara 0,41 sampai dengan 0,77 (Salim, Sudharma, Kusumaratna, \& Hidayat, 2007).

\section{Prosedur Penelitian}

Penelitian ini telah ditinjau dan disetujui oleh Unit Penelitian dan Pengabdian Kepada Masyarakat Fakultas Psikologi Universitas Padjadjaran dan juga Dewan Direksi PT. X untuk dimanfaatkan dalam program persiapan masa pensiun. Teknik pengumpulan data yang dilakukan dalam penelitian ini adalah survei dimana peneliti melakukan perekrutan partisipan yang memenuhi kriteria inklusi dalam dalam 3 (tiga) tahap, yaitu pada tanggal 11 Februari 2014, 20 Mei 2014, dan 10 Juni 2014 sebagaimana jadwal pembekalan masa persiapan pensiun. Partisipan memberikan pernyataan kesediaan dan melakukan pengisian kuesioner secara bersamaan di ruangan yang dipandu oleh tim peneliti.

\section{Analisis Data}

Semua analisis dan pengolahan data dilakukan dengan menggunakan SPSS versi 18. Statistik deskriptif digunakan untuk menggambarkan data demografis dari partisipan dan juga untuk menampilkan data deskriptif berupa nilai rata-rata dari sikap terhadap pensiun, perencanaan pensiun, dan kualitas hidup. Hubungan antara karakteristik demografis dengan sikap terhadap pensiun, perencanaan pensiun, dan kualitas hidup diuji dengan menggunakan Chi-square untuk variabel kategorial dan T-test untuk variabel kontinum. Multivariate regression analysis juga digunakan untuk menganalisis hubungan antara sikap terhadap pensiun, perencanaan pensiun, dan kualitas hidup.

\section{HASIL DAN PEMBAHASAN}

\section{Karakteristik Partisipan}

Penelitian ini melibatkan 322 partisipan. Terdapat 22 partisipan yang datanya tidak lengkap, sehingga data yang dianalisis adalah data dari 300 partisipan. Mayoritas partisipan adalah laki-laki (94\%), usia ratarata 53 tahun, dan telah memiliki pengalaman bekerja rata-rata selama 26,9 tahun. Sebagian besar dari mereka menikah $(97 \%)$ dan memiliki pendidikan SMA atau sederajat $(83 \%)$, sementara hanya sebagian kecil saja yang memiliki latar belakang pendidikan sekolah tinggi atau universitas (17\%). Hampir sepertiga dari partisipan melaporkan bahwa mereka memiliki penyakit yang didiagnosis oleh dokter dan memerlukan perhatian dan pengobatan khusus $(31 \%)$. Ringkasan dari karakteristik partisipan penelitian ini tergambar pada Tabel 1.

\section{Tabel 1. Karakteristik Partisipan}

\begin{tabular}{ll}
\hline Variabel & $\mathbf{n}(\boldsymbol{\%})$ \\
\hline Usia $(\mathrm{M} \pm \mathrm{SD})$ & $53,15 \pm 0,66$ \\
\hline Jenis kelamin & \\
\hline Laki-laki & $283(94 \%)$ \\
\hline Perempuan & $17(6 \%)$ \\
\hline Status pernikahan & \\
\hline Menikah & $293(97 \%)$ \\
\hline Lajang & $1(1 \%)$ \\
\hline Duda/janda & $6(2 \%)$ \\
\hline
\end{tabular}




\begin{tabular}{|c|c|}
\hline Pendidikan & \\
\hline $\begin{array}{l}\begin{array}{l}\text { Sekolah Menengah } \\
\text { sederajat) }\end{array}\end{array}$ & $250(83 \%)$ \\
\hline Perguruan tinggi (D3 atau S1) & $50(17 \%)$ \\
\hline $\begin{array}{l}\text { Memiliki penyakit (hasil diagnosis } \\
\text { dokter) }\end{array}$ & \\
\hline $\mathrm{Ya}$ & $94(31 \%)$ \\
\hline Tidak & $206(69 \%)$ \\
\hline Masa kerja (dalam tahun) $(\mathrm{M} \pm \mathrm{SD})$ & $26.9 \pm 6.5$ \\
\hline Rentang (tahun) & $3-37$ \\
\hline
\end{tabular}

\section{Perencanaan Pensiun, Sikap terhadap Pensiun, dan Kualitas Hidup}

Gambaran deskriptif mengenai perencanaan pensiun, sikap terhadap pensiun, dan kualitas hidup dari partisipan tertera pada Tabel 2 .

Tabel 2. Skor Perencanaan Pensiun, Sikap terhadap Pensiun, dan Kualitas Hidup

\begin{tabular}{lc}
\hline Aspek & Mean \pm SD \\
\hline $\begin{array}{l}\text { Perencanaan terhadap masa } \\
\text { Pensiun }\end{array}$ & $4,4 \pm 1,2$ \\
\hline Sikap terhadap Pensiun & $3,4 \pm 0,8$ \\
\hline $\begin{array}{l}\text { Kepuasan atas informasi } \\
\text { Pensiun }\end{array}$ & $3,5 \pm 0,8$ \\
\hline
\end{tabular}

\begin{tabular}{lc}
\hline Kualitas Hidup & \\
\hline Kualitas hidup secara umum & $3,6 \pm 0,6$ \\
\hline Kesehatan umum & $3,5 \pm 0,8$ \\
\hline Fisik & $14,6 \pm 1,7$ \\
\hline Psikologis & $14,4 \pm 1,8$ \\
\hline Sosial & $14,1 \pm 2,2$ \\
\hline Lingkungan & $13,3 \pm 1,7$ \\
\hline
\end{tabular}

Sebanyak 130 partisipan (43\%) memiliki perencanaan terhadap masa pensiun di atas rata-rata, sedangkan mayoritas dari partisipan hanya sedikit yang memiliki perencanaan terhadap masa pensiun mereka.

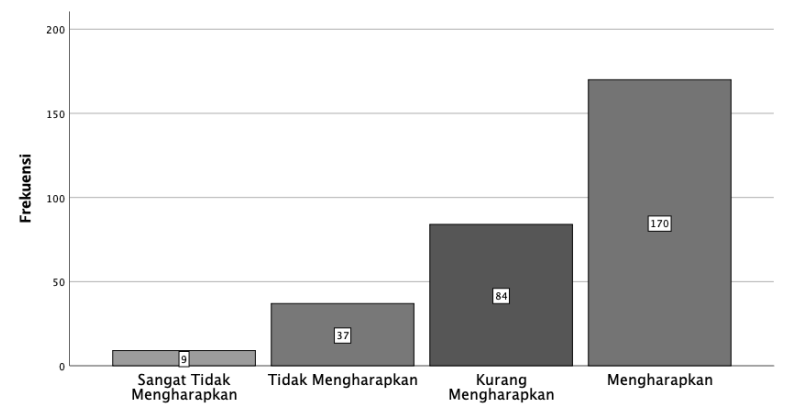

Gambar 1. Sikap terhadap masa pensiun

Data gambaran sikap partisipan terhadap masa pensiun menunjukkan bahwa sebanyak 9 (3\%) partisipan menyatakan sangat tidak mengharapkan masa pensiun, sebanyak $37(12 \%)$ partisipan menyatakan tidak mengharapkan masa pensiun, 84
(28\%) partisipan menyatakan kurang mengharapkan masa pensiun, dan sebagian besar partisipan, yaitu sebanyak 170 (57\%) menyatakan mengharapkan masa pensiun.

Dalam hal tingkat kepuasan mengenai informasi pensiun yang diberikan oleh perusahaan, diperoleh hasil bahwa ada sebanyak $5(2 \%)$ partisipan menyatakan sangat tidak memuaskan, $18 \quad(6 \%)$ partisipan menyatakan tidak memuaskan, 118 (39\%) partisipan menyatakan cukup, 142 (47\%) partisipan menyatakan memuaskan, dan $17(6 \%)$ partisipan menyatakan sangat memuaskan.

Resume skor kualitas hidup partisipan tergambar pada Tabel 2. Partisipan penelitian yang merupakan karyawan dalam masa persiapan pensiun memiliki skor yang relatif sama dalam kualitas hidup secara umum, kesehatan umum, dan semua domain kualitas hidup dibandingkan dengan norma populasi umum di Indonesia (Purba et al., 2018).

\section{Hubungan Sikap terhadap Pensiun, Persiapan Pensiun, dan Kualitas Hidup \\ Hasil analisis regresi yang menempatkan sikap} terhadap pensiun dan perencanaan pensiun sebagai prediktor, sedangkan outcome variabel adalah kualitas hidup, menunjukkan bahwa perencanaan pensiun adalah prediktor yang signifikan untuk domain fisik ( $\beta=0,22, p=0,01)$, domain psikologis $(\beta=0,4, p=0,01)$, dan domain lingkungan $(\beta=0,24, p=0,01)$ dari kualitas hidup. Namun, sikap terhadap pensiun tidak signifikan secara statistik.

\section{Hubungan Faktor Demografis dengan Sikap terhadap Pensiun, Perencanaan Pensiun, dan Kualitas Hidup \\ Latar belakang demografis partisipan tidak} menunjukkan perbedaan skor yang berarti dalam sikap terhadap pensiun dan perencanaan pensiun. Dari hasil T-test menunjukkan bahwa partisipan wanita memiliki nilai rata-rata yang lebih tinggi dalam skor kualitas hidup secara umum $(\mathrm{t}=-2,52, \mathrm{p}=0,02)$, juga domain fisik $(\mathrm{t}=-2,79, \mathrm{p}=0,01)$, domain sosial $(\mathrm{t}=-2,74, \mathrm{p}=$ $0,01)$, dan domain lingkungan $(\mathrm{t}=-3,45, \mathrm{p}=0,01)$ dari kualitas hidup dibandingkan dengan partisipan lakilaki. Partisipan dengan tingkat pendidikan perguruan tinggi memiliki nilai rata-rata yang lebih tinggi dalam kualitas hidup secara umum $(\mathrm{t}=-3,02, \mathrm{p}=0,01)$, juga domain fisik $(\mathrm{t}=-2,29, \mathrm{p}=0,02)$, domain psikologis $(\mathrm{t}=-$ $3,04, \mathrm{p}=0,01)$, domain sosial $(\mathrm{t}=-2,37, \mathrm{p}=0,02)$, dan domain lingkungan $(\mathrm{t}=-3,98, \mathrm{p}=0,01)$ dari kualitas hidup jika dibandingkan dengan partisipan yang berpendidikan menengah. Partisipan yang tidak mempunyai penyakit memiliki nilai rata-rata yang lebih tinggi dalam kesehatan secara umum $(\mathrm{t}=2,69, \mathrm{p}=$ $0,01)$, juga domain fisik $(\mathrm{t}=-3,37, \mathrm{p}=0,01)$ dan domain sosial $(\mathrm{t}=-2,98, \mathrm{p}=0,01)$ dari kualitas hidup jika dibandingkan dengan partisipan yang menyatakan mempunyai penyakit. 


\section{DISKUSI}

Hasil pengolahan data deskriptif menemukan bahwa hampir setengah partisipan menyatakan bahwa mereka memiliki sikap yang cenderung negatif terhadap masa pensiun (tidak atau kurang mengharapkan masa pensiun). Hal ini menjadi temuan yang penting untuk diperhatikan karena partisipan saat ini sudah berada 1-2 tahun menjelang pensiun yang seharusnya telah memiliki sikap yang positif akan masa pensiunnya. Hasil ini sejalan dengan penelitian sebelumnya yang dilakukan pada pegawai negeri sipil yang tengah menjalani masa persiapan pensiun di Kabupaten Tegal, Indonesia, yang menunjukkan bahwa hanya sebagian kecil pegawai yang memiliki sikap positif terhadap masa pensiun yang akan dihadapinya (Kusumarini, 2006). Data tersebut menunjukkan bahwa karyawan yang sedang dalam masa persiapan pensiun, baik di perusahaan swasta maupun pegawai negeri sipil, masih belum memiliki sikap yang positif terhadap masa pensiun yang akan dihadapinya dalam waktu dekat.

Perencanaan masa pensiun merupakan hal yang penting dalam keberhasilan seseorang melewati masa transisi dengan baik. Meskipun demikian, terdapat sepertiga partisipan yang menyatakan bahwa dirinya masih kurang mempersiapkan masa pensiunnya. Kondisi ini perlu disikapi dan ditanggapi secara serius oleh perusahaan maupun institusi, karena penelitian sebelumnya menemukan bahwa pegawai yang telah mendekati masa pensiun harus sudah memiliki komitmen yang kuat dan memiliki rencana yang konkret untuk diterapkan pada masa pensiunnya agar bisa beradaptasi dengan baik (Schlossberg, 2009). Pada populasi sekarang ini, kurangnya perencanaan mungkin terjadi karena partisipan belum memiliki gambaran dan rencana yang jelas mengenai aktivitas atau peran yang akan dilakukan ketika mereka memasuki masa pensiunnya. Masa pensiun merupakan masa yang penuh tekanan karena seseorang akan dihadapkan dengan banyak perubahan dan diperlukan persiapan yang baik untuk menyikapi semua perubahan tersebut. Meskipun demikian, kecemasan dan kebingungan pegawai dalam menghadapi masa transisi menuju pensiun dapat ditangani dengan adanya kebijakan, prosedur, dan program yang terstruktur dari perusahaan atau institusi (Fehr, 2012).

Hasil analisis menunjukkan bahwa perencanaan seseorang terhadap masa pensiunnya merupakan prediktor yang menentukan kualitas hidup individu yang sedang dalam masa persiapan pensiun, baik dalam aspek fisik, psikologis, maupun lingkungan. Penelitianpenelitian sebelumnya menemukan salah satu faktor psikososial yang memiliki kontribusi besar terhadap kesuksesan dan keseriusan seseorang dalam menyusun perencanaan masa pensiun adalah adanya tujuan yang jelas. Misalnya, ditemukan bahwa orang yang mengikuti pelatihan pembuatan tujuan menunjukkan skor lebih baik dalam perencanaan dan menabung setelah 12 bulan dibandingkan dengan mereka yang tidak (Hershey, Mowen, \& Jacobs-Lawson, 2003). Penelitian lain juga menemukan bahwa seseorang yang memiliki tujuan finansial yang kuat akan melakukan penyimpanan dana (menabung) secara lebih banyak untuk persiapan masa pensiun mereka (Neukam \& Hershey, 2003). Hal ini menunjukkan bahwa bagian terpenting dalam proses persiapan masa pensiun adalah memiliki tujuan yang pasti. Mereka yang memiliki tujuan akan melakukan perencanaan masa pensiun secara lebih baik dan bisa menyesuaikan diri dengan masa pensiun yang akan dihadapinya, serta memiliki kualitas hidup yang lebih baik.

Penelitian sebelumnya mengenai sikap terhadap pensiun menemukan bahwa sikap terhadap pensiun merupakan salah satu faktor yang menentukan bagaimana keberhasilan adaptasi dan kesejahteraan seseorang (Shultz \& Wang, 2011). Akan tetapi, pada penelitian ini sikap terhadap pensiun tidak terbukti secara signifikan sebagai prediktor yang menentukan kualitas hidup. Hal ini bisa disebabkan karena karyawan yang menjadi sampel dalam penelitian ini memiliki variabilitas dalam sikap terhadap masa pensiun, sedangkan kualitas hidup mereka cenderung tinggi dikarenakan adanya sistem penggajian, jaminan, dan remunerasi yang cukup baik di perusahaan $\mathrm{X}$ tempat mereka bekerja saat ini. Selain itu, partisipan yang terlibat adalah karyawan yang telah memasuki waktu pensiun, sehingga hal ini sejalan dengan penelitian sebelumnya yang menemukan bahwa karyawan yang pensiun sesuai dengan batas usia atau mengajukan pensiun dini secara sukarela memiliki kesehatan mental dan pemfungsian secara fisik yang lebih tinggi jika dibandingkan dengan karyawan yang pensiun dikarenakan sakit (Jokela et al., 2010).

Hasil analisis tambahan atas data demografis menunjukkan bahwa partisipan wanita, memiliki pendidikan tingkat universitas, dan tidak memiliki riwayat penyakit memiliki kualitas hidup yang lebih tinggi. Meskipun demikian, tidak ada latar belakang demografis yang membedakan sikap terhadap pensiun dan perencanaan masa pensiun. Hal ini menunjukkan bahwa persiapan menuju masa pensiun merupakan masa yang penuh tekanan bagi hampir semua orang, maka dari itu diperlukan adanya peran aktif dari institusi atau perusahaan untuk membuat program edukasi dan konseling secara terstruktur untuk setiap karyawan yang menghadapi masa persiapan pensiun (Willet, 2008).

Penelitian ini memiliki beberapa keterbatasan, diantaranya: (1) penelitian dilakukan di perusahaan automotif dengan mayoritas partisipan adalah laki-laki, (2) penelitian dilakukan pada satu jenis perusahaan, sehingga hasil penelitian ini perlu diekstrapolasi dengan penelitian lebih lanjut yang menggunakan partisipan dari berbagai kategori institusi agar bisa memperoleh kesimpulan yang lebih komprehensif. 


\section{SIMPULAN}

Dari penelitian ini dapat disimpulkan bahwa perencanaan pensiun adalah prediktor dari kualitas hidup karyawan yang sedang dalam masa persiapan pensiun, sedangkan sikap terhadap pensiun tidak. Hal ini memberi implikasi bahwa terlepas dari sikap positif maupun negatif terhadap masa pensiun, sangat penting diadakan penyediaan program edukasi untuk membantu individu melakukan perencanaan masa pensiun secara terstruktur agar mereka bisa menyesuaikan diri dengan masa pensiun secara lebih baik dan memiliki kualitas hidup yang baik.

\section{UCAPAN TERIMA KASIH}

Ucapan terima kasih kami sampaikan kepada Pengurus Dana Pensiun PT. X dan juga seluruh partisipan yang sudah berkenan membantu dan berpartisipasi dalam pelaksanaan penelitian ini.

\section{DAFTAR PUSTAKA}

Adams, G. A., \& Rau, B. L. (2011). Putting Off Tomorrow to Do What You Want Today: Planning for Retirement. American Psychologist, 66(3), 180 192.

Alvarenga, L. N., Kiyan, L., Bitencourt, B., \& Wanderley, K. (2009). The impact of retirement on the quality of life of the elderly. Rev Esc Enferm USP, 43(3), 794-800.

Badan Kepegawaian Negara. (2014). Surat Kepala Badan Kepegawaian Negara tentang Batas Usia Pensiun Pegawai Negeri. Jakarta.

Fehr, R. (2012). Is Retirement Always Stressful? The Potential Impact of Creativity. American Psychologist, 66(5), 406.

Foster, T. W. (2008). Depression, Anxiety and Attitude toward Retirement as Preditors of Wellness for Workers Nearing Retirement. (Doctor of Philosophy), Kent State University, Kent.

Hershey, D. A., Mowen, J. C., \& Jacobs-Lawson, J. M. (2003). An experimental comparison of retirement planning intervention seminars. Educational Gerontology, 29, 339-359.

Hessel, P. (2016). Does retirement (really) lead to worse health among European men and women across all educational levels? Soc Sci Med, 151, 1926.

Jokela, M., Ferrie, J. E., Gimeno, D., Chandola, T., Shipley, M. J., Head, J., . . Kivimaki, M. (2010). From Midlife to Early Old Age: Health Trajectories Associated With Retirement. Epidemiology, 21, 284-290.

KBBI (2016). Kamus Besar Bahasa Indonesia (KBBI). [Online] Available at: http://kbbi.web.id/pensiun, [Diakses 20 Februari 2016].
Kubicek, B., Korunka, C., Raymon, J. M., \& Hoonakker, P. (2011). Psychological Well-Being in Retirement: The Effects of Personal and Gendered Contextual Resources. Journal of Occupational Health Psychology, 16(2), 230-246.

Kusumarini, C. D. (2006). Pengaruh Sikap Menghadapi Pensiun Terhadap Penyesuaian Diri Menjelang Pensiun. Skripsi. Universitas Negeri Semarang, Semarang.

Lim, G. (2003). An empirical study of older workers' attitudes towards the retirement experience. Employee Relations, 25(4), 330-346.

Mutran, E. J., Reitzes, D. C., \& Fernandez, M. E. (1997). Factors that Influence Attitudes Toward Retirement. Research on Aging, 19(3), 251-273.

Neukam, K. A., \& Hershey, D. A. (2003). Financial inhibition, financial activation, and saving for retirement. Financial Services Review, 12, 19-37.

Purba, F. D., Hunfeld, J. A. M., Iskandarsyah, A., Fitriana, T. S., Sadarjoen, S. S., Passchier, J., et al. Quality of life of the Indonesian general population: Test-retest reliability and population norms of the EQ-5D-5L and WHOQOL-BREF. PLoS One. 2018.

Pusat Data dan Informasi Kementerian Kesehatan RI. (2016). Situasi Lanjut Usia (Lansia) di Indonesia.

Reitzes, D. C., \& Mutran, E. J. (2006). Lingering identities in retirement. Sociological Quarterly, 47, 333-359.

Salim, O. C., Sudharma, N. I., Kusumaratna, R. K., \& Hidayat, A. (2007). Validitas dan reliabilitas World Health Organization Quality of Life-BREF untuk mengukur kualitas hidup lanjut usia. Universa Medicina, 26(1), 27-38.

Schlossberg, N. K. (2009). Revitalizing retirement: Reshaping your identity, relationships and purpose. Washington, DC American Psychological Association.

Shaughnessy, J. J., Zechmeister, E. B., \& Zechmeister, J. S. (2012). Research methods in psychology (9 ed.). New York: McGraw-Hill.

Shultz, K., \& Wang, M. (2011). Psychological Perspectives on the Changing Nature of Retirement. American Psychologist, 66(3), 170-179.

Szinovacz, M. E. (2003). Contexts and pathways: Retirement as institution, process, and experience. In G. A. Adams \& T. A. Beehr (Eds.), Retirement: Reasons, processes, and results New York: Springer.

Turner, M. J. (1989). Factors Influencing Attitude Toward Retirement and Retirement Planning among Midlife University Employees (Doctor of Philosophy), Texas Tech University, Texas.

Weiner, I. B. (2003). Handbook of psychology. In Richard M. Lerner, M. Ann Easterbrooks \& Jayanthi Mistry (Eds.). Developmental Psychology (Vol. 6). Danvers: John Wiley \& Sons, Inc. 
Willet, M. (2008). A new model for retirement education and counseling. Financial Services Review, 17(2), 105.

World Health Organization. (1997). WHOQOL Measuring Quality of Life. Division of Mental Health and Prevention of Substance Abuse WHO, Geneva. 